\title{
Inquérito sorológico da brucelose canina através da utilização de antígeno externo e interno de Brucella canis e Brucella ovis
}

\section{Serodiagnosis of canine brucellosis using external and internal antigens of Brucella canis and Brucella ovis}

\author{
Teresinha Ferreira, ${ }^{*}$ Miguel Amaral Mandelbaum, ${ }^{* *}$ Ana Paula Lopes Marques, ${ }^{* *}$ Helenita Marques Torres, ${ }^{*}$ \\ Márcio José de Figueiredo, ${ }^{*}$ Cáthia Maria Barrientos Serra, ${ }^{*}$ Maria Helena Cosendey de Aquino*
}

\begin{abstract}
Resumo
O objetivo desse estudo foi investigar a ocorrência da brucelose canina na cidade do Rio de Janeiro utilizando-se a técnica de imunodifusão em gel de agarose.Antígenos externo e interno de Brucella canis e Brucella ovis foram previamente preparados e um antígeno comercial usado para diagnóstico da brucelose canina foi também utilizado.Amostras de soro de 316 cães coletadas aleatoriamente foram examinadas. Oito amostras (2,53\%) foram positivas no teste utilizando-se antígeno externo de B. canis e $B$. ovis e sete amostras $(2,2 \%)$ foram confirmadas com o antígeno comercial.Três amostras $(0,95 \%)$ foram positivas para todos os antígenos testados. Antígenos externo e interno devem ser usados nos testes sorológicos para diagnóstico da brucelose canina para detecção precoce e obtenção de resultados mais precisos, respectivamente.
\end{abstract}

Palavras-chave: brucelose canina, teste de imunodifusão, antígenos.

\begin{abstract}
The present study was designed to carry out a serologic investigation of canine brucellosis by using agar gel immunodiffusion test in the Rio de Janeiro city. External and internal antigens of B. canis and B. ovis were previously prepared and a commercial kit used for canine brucellosis diagnosis, was also employed. Random samples of 316 dogs were examined. Eight samples $(2,53 \%)$ were positive by using external antigen of $B$. canis and $B$. ovis. Seven samples $(2,2 \%)$ were positive using the commercial antigen also, and three samples $(0,95 \%)$ were positive for all the antigens employed. External and internal antigens must be used for early detection and accurate results, respectively.
\end{abstract}

Keywords: canine brucellosis, immunodiffusion test, antigens.

A maioria dos cães acometidos pela brucelose é assintomática, sendo o diagnóstico clínico da infecção bastante difícil. O único método realmente seguro para o diagnóstico da enfermidade é o isolamento do agente, embora vários fatores inerentes às técnicas de realização e à evolução da própria enfermidade afetem o sucesso desse procedimento. Os testes sorológicos são os mais comumente utilizados para avaliar o estado do cão antes do cruzamento ou quando se suspeita de brucelose canina (López et al., 2006), mas necessitam de criteriosa avaliação na interpretação dos resultados dependendo do tipo de antígeno utilizado, da fase evolutiva da doença e de infecções com bactérias diferentes de Brucella que podem reagir cruzadamente (Watari et al., 2007). No Brasil, a imunodifusão em gel de agarose (IDGA) é o teste realizado rotineiramente e utiliza antígeno externo constituído de proteínas e lipopolissacarídios extraídos da parede celular de B. ovis. Entretanto, testes que empregam antígenos de parede de $B$. ovis têm sido questionados pelas reações cruzadas que determinam, pois é compartilhado por outras bactérias Gram-negativas e nas fases iniciais e finais da doença podem revelar resultados fracamente positivos. Esse trabalho teve como objetivo o emprego da IDGA, utilizando-se comparativamente antígenos externos e internos de $B$. canis e $B$. ovis para investigação deste agente na população canina no município do Rio de Janeiro.

Foram investigados 316 soros de cães, 141 provenientes de fêmeas e 175 de machos com idades variando entre 11 meses e 9 anos, sem informação sobre o histórico clínico. Utilizaramse antígenos externos de $B$. ovis e $B$. canis como teste de triagem. Os antígenos internos de $B$. ovis e $B$. canis assim como o antígeno externo comercial foram utilizados para confirmação dos animais positivos. Os antígenos internos e externos de $B$. canis e $B$. ovis foram previamente preparados

\footnotetext{
* Professores do Departamento de Saúde Coletiva Veterinária e Saúde Pública da Faculdade de Veterinária da Universidade Federal Fluminense. Rua Vital Brazil Filho, 64, Vital Brazil. CEP 24230-340, Niterói, RJ - Brasil

** Alunos do curso de graduação da Faculdade de Veterinária da UFF
} 
e padronizados no Laboratório de Doenças Infecciosas dos Animais Domésticos da Faculdade de Veterinária-UFF a partir das cepas RM/66 de B. canis e REO 198 de B. ovis seguindose a metodologia descrita por Zoha e Carmichael (1982). Estas cepas também foram utilizadas na inoculação de coelhos para a obtenção de soro hiperimune para serem utilizados como controle positivo nos testes sorológicos. Os testes de IDGA foram realizados de acordo com a Organização Mundial da Saúde (Alton et al., 1988).

Dentre os 316 animais testados, oito foram positivos (2,53\%) no teste de triagem com antígenos externos tanto de $B$. ovis quanto de $B$. canis fabricados no nosso laboratório, sugerindo que ambas as espécies podem ser utilizadas na confecção do antígeno para a reação de IDGA. Esse resultado é semelhante ao encontrado em outras cidades do Brasil, como 3,6\% em São Paulo-SP (Sandoval et al., 1976), 1,43\% em Salvador-BA (Pereira Filho et al., 1978) e 1,3\% em Belo Horizonte-MG (Godoy et al., 1977). A população investigada nesse estudo foi aleatória e as amostras foram provenientes de cães domiciliados cujos soros foram enviados para análises laboratoriais diversas. Uma diferença significativa nos resultados sorológicos para a brucelose canina foi observada por Brow et al. (1976) quando considerou-se a procedência dos animais, variando de $1 \% \mathrm{em}$ cães de estimação e $8 \%$ em cães vadios, revelando uma menor ocorrência nos cães domiciliados, onde a reprodução é controlada, tal como se verificou nesse estudo.

Dentre os oito soros positivos na triagem, sete $(2,2 \%)$ foram confirmados pelo teste comercial. As diferentes condições de extração e preparo dos antígenos externos e uma provável diferença nas concentrações deve ser considerada na análise desse resultado. Quando se utilizaram antígenos internos de B. ovis e $B$. canis, três soros $(0,95 \%)$ foram positivos, sendo portanto positivos para todos os antígenos testados. A utilização de antígeno interno para detecção da brucelose reduz a possibilidade de reações cruzadas. No entanto, as amostras não confirmadas por este antígeno poderiam estar relacionadas com a infecção recente, quando as aglutininas correspondentes ao antígeno interno ainda estariam em nível inferior ao detectável, pois as respostas sorológicas aos antígenos internos na brucelose canina só são detectadas após um período médio de 16 semanas (Zoha e Carmichael,1982). A prevalência da brucelose canina é variável segundo a região e o método de diagnóstico empregado, considerando que não há um protocolo padrão para o diagnóstico sorológico e nem um consenso sobre a escolha da melhor técnica. Como não tivemos acesso aos animais investigados, não foi possível realizar a hemocultura e obter informações sobre os dados clínicos, o que seria importante na análise dos resultados. Com o intuito de minimizar a magnitude do problema em relação aos animais verdadeiramente positivos para a brucelose canina e evitar possíveis reações cruzadas com outras bactérias Gram-negativas, sugere-se a realização de teste sorológico de triagem utilizando-se antígenos externos de $B$. canis ou $B$. ovis para detecção precoce e confirmação posterior através da utilização de antígenos internos.

\section{Agradecimentos}

Os autores agradecem à Fundação de Amparo à Pesquisa do Estado do Rio de Janeiro - FAPERJ pelo auxílio financeiro.

\section{Referências}

ALTON, G.G.; JONES, L.M.; ANGUS, R.D.; VERGER, J.M. Techniques for the Brucellosis Laboratory. Paris: INRA, 1988, $189 \mathrm{p}$.

BROW, J.; BLUE, J.L.; WOOLEY, R.E.; DRESSEN, D.W. Brucella canis infectivity rates in stray and pet dog populations. Am. J. Public Health. v. 66, n. 9, p. 889-891, 1976.

GODOY, A.M.; PERES, J.N.; BARG, L. Isolamento de Brucella canis em Minas Gerais, Brasil. Arq. Esc. Vet. UFMG, v. 29, n. 1, p. 35-42, 1977. LOPEZ, G.;ESCOBAR, G.I.;AYALA, S.M.; LUCERO, N.E. Detection of antibodies to Brucella ovis in sheep milk using $B$. ovis and $B$. canis antigen. Vet. Microbiol. v. 116, n. 4, p. 232-238, 2006.

PEREIRA FILHO, M.; SILVA, J.A H.; ROCHA, J.V.N. Estudo da incidência da Brucelose canina na região metropolitana de Salvador. In: CONGRESSOBRASILEIRO de MEDICINA VETERINÁRIA,1978, Salvador, Bahia. Anais... 1978. p. 32 .
SANDOVAL, L.A; CONRADO RIBEIRO, L.A.;AMARAL, L.B.S.;FEITOSA, M.H.; BAZAN. J.M. Incidência da Brucelose canina na cidade de São Paulo. Biologico. V. 42, p. 128-132, 1976.

WATARI, M.; KIM, S.; YAMAMOTO,J.; MIYAHARA,K.; KAZAMA, M.; MATSUOKA, S.; CHIMURA, S.; SUZUKI,H.A. Rapid agglutination assay for canine brucelosis using coated beads. J.Vet.Med.Sci. v. 60, p. 477-480, 2007.

ZOHA, S.J.; CARMICHAEL, L.E. Serological Responses of Dogs to Cell Wall and Internal Antigens of Brucella canis (B. canis). Vet. Microb. v. 7, p. $35-50,1982$. 